\title{
Green Supply Chain Newsvendor Model and Analysis under Multiplicative Random Demand
}

\author{
Yi Wang ${ }^{1 *}$, Jian Hu${ }^{1}$, XiaohuiYuan ${ }^{2}$, Yang Liu ${ }^{1}$ \\ ${ }^{1}$ College of Science, Tianjin University of Commerce, Tianjin300134, China \\ ${ }^{2}$ School of Economics, Capital University of Economics and Business, Beijing 100070, China \\ *Corresponding Author.
}

\begin{abstract}
In this paper, we investigate the performance of green supply chain newsvendor model under multiplicative random demand. In our model, the green supply chain consists of one manufacturer and one retailer. The manufacturer acts as a leader, which decides the variables: production quantity, wholesale price and green-level; the retailer acts as a follower, decides on the retail price. Centralized and decentralized optimal solutions are obtained to optimize the manufacturer's production, stocking and green-level decision while anticipating the retailer's price optimization decision. Through research, it is found that the stocking factor decreases with the increasing price elasticity and is not affected by the green-level elasticity; Lower price elasticity will increase the optimal selling price of the green product, while green-level elasticity has no effect on the price; Larger price elasticity or green-level elasticity will increase the optimal green-level of the green product; Lower price elasticity or higher green-level elasticity will increase the overall profitability of the supply chain; Profit sharing between manufacturer and retailer under the decentralized model only depends on price elasticity and green-level elasticity; The greater price elasticity, the more beneficial to the retailer, the greater the green-level, the more beneficial to the manufacturer.
\end{abstract}

Keywords: Green supply chain,random demand, newsvendor model

\section{Introduction}

What the world needs, is an environmentally friendly, logistically feasible and economically responsible green and sustainable products. As the increasing competition of market, technology and our environment, green products are more welcomed by consumers. Supply chain management containing green products becomes a frontier challenge for world organizations and partners. To survive in the competitive environment, companies have to investigate on producing promising products. How to raise their profits and deduce their costs become the key of each companies (see Shankar et al. ${ }^{[1]}$; Kannan, ${ }^{[2]}$ ).

In order to win the sustainable development, many companies focus on designment of green supply chain. It reveals that combination of theoretical design and practical application has achieved excellent performance (see Golden et al. ${ }^{[3]}$, Pan et al. ${ }^{[4]}$ ). Many famous companies such as Li Ning, Apple Inc., IBM, and so on, have wined the advantages in the intense market competition.

In the practice of green supply chain design and management, aiming to establish an international image, companies are competing to set a benchmark. For example, more and more leading companies in USA are committed to the implementation of global environmental standards, and to require all branches around the world to pass the ISO14001 certification. Some green supply chain management pacesetters have also positioned themselves as leaders of green supply chain management. For example, HTC's main goal is to become a "worldlevel" leading companies in environmental issues, which has been successfully carried out. These companies not only set their own goals strict than the relevant laws and regulations of saving resources, reducing waste, avoiding pollution and green production design, but also actively improve the environmental protection level of the whole

ISSN: 0010-8189

(C) CONVERTER 2021

www.converter-magazine.info 
supply chain and even the whole industry system. In order to promote the development towards the green supply chain field, the US Environmental Protection Agency (US-EPA) has done a lot of work to confirm and to support the development of the green supply chain management. For example, GM company is recognized by US-EPA as one of the pacesetters in the development of green supply chain management. In 2019, the Ministry of Commerce in China issued several documents to accelerate the construction of green supply chain management, such as,"Pilot work plan for the construction of a waste-free city", "Development plan of Dawan District in Guangdong, Hong Kong and Macao", and so on.

Because of consumers' income, purchase preference, price sensitivity, green-level sensitivity, it is difficult to predict the demand of green products. In addition, restricted to companies' own technology, it is hardly to predict changes in market demand, especially for green products. For example, the latest type of semiconductor components, belonging to one kind of electronic green products, in a quarter may have a deviation of up to $80 \%$ between the actual demand and the predicted value ${ }^{[5]}$. This implies that random demand will not only affect to companies' profits, but only to whole channels' profits. Moreover, the effect may amplified from downstream member to upstream one. This is called Bullwhip effect. How to minimize the risk brought by random demand, has become the key of supply chain management, which is also concerned by many researchers. For example, HewlettPackard, General Motors, Volkswagen and Boeing are all companies that have successfully applied supply chain management strategies.

Our paper aims to investigate the optimal decisions of green supply chain under random demand. The research will be helpful to develop and improve theory and method of supply chain management. In fact, this also provide theoretical guidance for supply chain members. Speaking of the contribution of this article, we believe that our paper contributes to the optimal decision of supply chain based on green product under multiplicative random demand. We discuss the impact of price elasticity and green-level elasticity on their optimal decisions (including production quantity, wholesale price, production green-level, and retail price), as well as the supply chain performance. On the practical level, these theoretical results and the relationship between supply chain design and stocking factor can provide companies with decision-making solutions that can effectively help them maximize profits.

The rest of this paper is organized as follows. In Section II, related literature is presented and our contribution is given. In Section III, we investigated the green supply chain newsvendor model, and studied the optimal decisions of the manufacturer and retailer under the multiplicative random demand in centralized and decentralized structure. Section IV shows the comparison of the centralized channel and decentralized channel. Numerical results and conclusions and future work directions are presented in Section V and VI. Finally, all the proofs are in Section VII.

\section{Literature Review}

Our paper mainly focuses on a green supply chain with centralized and decentralized structure under random demand models. Before introducing the model, we will review a large number of related literature covered in this article, including green supply chain management and random demand supply chain management.

\subsection{Green supply chain management}

Currently, there are many domestic and foreign scholars searching on green supply chain management, especially on optimal strategies. Cao et al. ${ }^{[6]}$ proposed two coordination strategies by considering consumer demand caused by green products utility diversity. These two strategies are based on the Stackelberg game and cooperative decision-making separately. For the latter, by Nash coordination approach, they built a nonlinear pricing model and each member achieved Stackelberg-equilibrium profits Pareto improvement. Sheu ${ }^{[7]}$ investigated the problem of negotiations between producers and reverse-logistics suppliers for cooperative agreements under government intervention. They sought equilibrium negotiation strategies to players, and indicated that financial intervention by

ISSN: 0010-8189

(C) CONVERTER 2021

www.converter-magazine.info 
a government generates a significant effect on the relative bargaining power of green supply chain members in negotiations. Jin and Wang ${ }^{[8]}$ built game model for common products and green products in the remanufacturing green supply chain to speculate the optimal strategies of companies and the optimal incentive strategy of government. On the one hand, they analyzed the optimal equilibrium decision in a variety of circumstances. On the other hand, basing on the recovery percent or recovery quantity, they contrasted the validity of government's subsidy incentive strategies. Sheu and Chen ${ }^{[9]}$ constructed a three-stage supply chain model to explore how the governmental intervention effects the performance of their members. They gotequilibrium strategies of governmental and chain members. Analytical results suggested that the government should adopt green taxation and subsidization to ensure non-negative profits.

In addition, scholars have fully studied the formulation of coordination contracts in green supply chain management. Ghosh and Shah ${ }^{[10]}$ build a supply chain consisting of one manufacturer and one retailer, and showed how green-level, retail price and channel profit are influenced by channel structures. They also proposed a two-part tariff contract to coordinate the green channel. Zhang et al. ${ }^{[1]}$ investigated the pricing and coordination issues of single-period green supply chain, and discussed the equilibrium decisions on the market demand that green products and non-green products co-exist with and substitute each other in centralized channel and decentralized channel. Ghosh and Shah ${ }^{[12]}$ explored supply chain coordination issues arising out of green supply chain initiatives, and explored the impact of cost sharing contract on the key decisions of supply chain members undertaking green initiatives. Through a game theoretic approach they showed how product green levels, prices and profits are influenced by cost sharing contract within the supply chains.

Li et al. ${ }^{[13]}$ discussed the pricing and greening strategies for a dual-channel green supply chain members in both centralized and decentralized cases by using the Stackelberg game model under a consistent pricing strategy. Furthermore, they compared the results in both single channel and dual-channel supply chains. Zhu et al. ${ }^{[14]}$ investigated a green supply chain with one manufacturer and one retailer. They represented the effects by supply chain structures, green product types and types of competition on the channel's decisions. Dai et al. ${ }^{[15]}$ designed a green supply chain to achieve energy-saving performance by forming research and development collaborations. They analyzed two typical cooperative behaviors (Cartelization and Cost-sharing contract) of the supply chain, and compared the performance among Cartelization, Cost-sharing contract and a benchmark of non-cooperation. They showed that the results relies on both the comparative efficiency which captures the technology difference between the members, and the effectiveness factor which measures the consumer green awareness and government subsidy. Song and Gao ${ }^{[16]}$ established a green supply chain with two kinds of revenue-sharing contracts under the centralized channel and the decentralized channel. By their analysis on the interval membership decision variables and the overall performance of the supply chain, they proposed a revenue-sharing contract to improve green-level of the products and overall profitability of the supply chain. Halat and Hafezalkotob ${ }^{[17]}$ applied a Stackelberg game theory to model carbon regulation policies in inventory decisions of a multi-stage green supply chain. They examined the effect of coordination and carbon regulations on inventory cost, carbon emission and the objective function of government. Giri et al. ${ }^{[18]}$ develop a competing supply chain with two green manufacturers and a retailer competing and cooperating with one another under the intervention of government. Asif et al. ${ }^{[19]}$ reviewed approaches of developing countries, finding that eco-design, green purchasing, green manufacturing and reverse logistics are four promising practices.

According to our best knowledge, random demand has not been considered as a variable in green supply chain management.

\subsection{Random demand supply chain management}

In a supply chain, random supply leads to two kinds of risks-supply side disruption and demand side disruption. Whether it is natural disasters or human factors, the problem of supply chain disruptions has attracted increasing attention of scholars. In reality, studies in history on randomness can always belong to one of these two situations or both (Baghalian et al. ${ }^{[20]}$; Matei et al. ${ }^{[21]}$; Azad and Hassini, ${ }^{[22]}$ ). For more information, one can see the book by

ISSN: 0010-8189

(C) CONVERTER 2021

www.converter-magazine.info 
Choi and Cheng ${ }^{[23]}$.

In order to avoid the risks caused by random demand, $\mathrm{Li}$ and $\mathrm{Liu}{ }^{[24]}$, $\mathrm{Hsu}$ and $\mathrm{Li}^{[25]}$, Alhaj et al. ${ }^{[26]}$ have systematically designed their supply chain. Chen and Chen ${ }^{[27]}$ models a Stackelberg game between a risk-averse original equipment manufacturer and a risk-neutral contract manufacturer to get the equilibrium pricing and ordering, based on conditional value-at-risk. They showed that the equilibrium balanced price and order can minimize the conditional value-at-risk of the original equipment manufacturer, and maximize the expected profit of the contract manufacturer. Sasan and Maryam ${ }^{[28]}$ presented that their model can support green supply chain network in different levels of randomness. Campanur et al. ${ }^{[29]}$ investigated a complex, multiechelon supply chain under random demand with a logistic nonlinear system. Bhakti et al. ${ }^{[30]}$ considered an agri-food supply chain with random demand. Shan et al. ${ }^{[31]}$ studies coordination of a supply chain under random demand for seasonal products, considering quality control and retailer's loss aversion behavior. Wu et al. ${ }^{[32]}$ considered the environmental investment decision in a green supply chain under random demand. They analyzed the influence of green uncertainty on each member's decision. Li et al. ${ }^{[33]}$ constructed a double echelon supply chain, and analyzed pricing strategies and profit coordination. Moreover, they studied the supply chain with random demand and asymmetric information, and found that this can obviously affect the equilibrium profits.

In addition, there are many other different aspects on random supply chain investigated by the scholars, such as random yield, random cost, random ordering, random collection quantity, and so on. Keren ${ }^{[34]}$ showed the singleperiod inventory problem: extension to random yield from the perspective of a supply chain. Yang et al. ${ }^{[35]}$ studied on supply chain ripple effect under random demand and production cost disruptions. Zhu and Wang ${ }^{[36]}$ studied the game analysis of a two-echelon supply chain with random yield. Zhang and Luo ${ }^{[37]}$ studied the problem of supply chain coordination under risk of random yield. Huang et al. ${ }^{[38]}$ investigated the government subsidy mechanism in agricultural supply chain considering capital constrain under random yield. Wang et al. ${ }^{[39]}$ studied on carbon reduction and pricing strategy of closed-loop supply chain considering random collection quantity. Ahmadi et al. ${ }^{\text {[40] }}$ proposed the optimal randomized ordering policies for a capacitated two-echelon distribution inventory system. Zhang and Zhang ${ }^{[41]}$ considered a two-period supply chain where the supplier with random cost learning sells products through a retailer who may keep market potential information private. Tang et al. ${ }^{[2]}$ investigated a supply chain network scheduling by considering merge decision with random order interference. Zare et al. ${ }^{\left[{ }^{[3]}\right.}$ considered a supply chain which includes a supplier facing random yield and multiple downstream retailers dealing with random demands. Anderson and Monjardino ${ }^{[4]}$ designed contracts in agriculture supply chains with random yield. Feng et al. ${ }^{[45]}$ considered a supply chain containing both random demand and random yield. They found that only when the capacity and the demand differ little, their upstream facility carries positive inventory.None of the aforementioned work consider random demand of green products in the context of a supply chain.

In this paper, we investigate a green supply chain under random demand. Specifically, we analyze how the two key parameters, namely, price elasticity index and green-level elasticity index, influence the performance of supply chain under centralized and decentralized structure.

\subsection{Summary of literature review}

Although many researchers have made contributions to green supply chain management, as far as we know, no scholars have considered management of green supply chain under random demand. Our work not only fills the existing gap, but also makes the following contributions:

- By studying green supply chain with centralized and decentralized structures under multiplicative random demand model, we show that there exists unique optimal decisions in both the centralized and decentralized channels.

- Theoretically, we prove that how the two key parameters-price elasticity and green-level elasticity affect optimal decisions and profit of both two members.

ISSN: 0010-8189

(C) CONVERTER 2021

www.converter-magazine.info 
Comparing to the existed literature, we adopt newsvendor model to study the random green supply chain, we expand the green supply chain management that has not been studied before.

\section{Green Supply Chain Newsvendor Model}

3.1 Model assumptions and descriptions

In our model, the supply chain contains a upstream manufacturer and a downstream retailer. The manufacturer decides on production quantity $q$, green-level $\theta$ and wholesale price $\omega$; and the retailer decides on retail price $p$. A single-period product is produced by the manufacturer and sold to the retailer at a wholesale price, and then, the retailer sold the product to consumers at a retail price. Consumers are sensitive to green products, and need to consider both price and green-level when buying products.

Inspired by $\mathrm{Li}$ et al. ${ }^{[46]}$, we make the following assumptions and notations in Table 1 , and we describe the optimal ones by adding a superscript "*” on original notations.

(1) We assume that our demand function has the multiplicative structure as

$$
D(p, \theta, \varepsilon)=y(p, \theta) \cdot \varepsilon .
$$

where $y(p, \theta)$ is a function representing an multiplicative demand curve, which is decreasing in retail price $p$ and increasing in production green-level $\theta$, having the form

$$
y(p, \theta)=a p^{-\alpha} \theta^{\beta} .
$$

where $a>0, \alpha>1$ (demand with high elasticity) and $0<\beta<2$. In the above formulation, the parameter $\alpha$ denotes price elasticity index, and the parameter $\beta$ denotes green-level elasticity index. The larger the value of $\alpha$, the more sensitive the demand on change of price. The larger the value of $\beta$, the higher the popularity of green products. The random variable $\varepsilon$ is distributed on $[A, B]$ and $B \geq A \geq 0 ; f(\cdot)$ is the probability density function; $F(\cdot)$ is the cumulative distribution function of $\varepsilon$.

(2)The manufacturer's producing cost of green products is denoted as $c$. In order to improve greenlevel of the product, the manufacturer need to invest in research and development (R\&D). We assume the cost of green product is $I \theta^{2}$, where $I$ is the green investment parameter.

(3)For the sake of simplicity, there is no salvage value and no disposal cost of any surplus products at end of the season. Also, there is no compensation if production quantity can't meet the requirement of market demand, but only the loss of revenue. Our assumptions that no salvage, no disposal cost and no compensation are reasonable for seasonable products or short-period products.

Table 1 Notations

\begin{tabular}{c|c}
\hline Notation & Explanation \\
\hline$p$ & retail price of the green product \\
\hline$\theta$ & green-level of the product \\
\hline$\varepsilon(p, \theta, \varepsilon)=y(p, \theta) \cdot \varepsilon$ & random variable defined on the range $[A, B]$ \\
\hline$I$ & the price and green-level sensitive linear random demand \\
\hline$f(\cdot)$ & probability density function of $\varepsilon$ \\
\hline$F(\cdot)$ & cumulative distribution function of $\varepsilon$, with $\bar{F}(\cdot)=1-F(\cdot)$ \\
\hline$h(x)$ & the failure rate function of demand distribution, with $h(x) \equiv f(x) /[1-F(x)]$ \\
\hline$g(x)$ & general failure rate function of demand distribution, with $g(x)=x h(x)$ \\
\hline$c$ & the cost of producing green products \\
\hline$q$ & production quantity of the manufacturer \\
\hline$\omega$ & wholesale price of the manufacturer to the retailer
\end{tabular}

ISSN: 0010-8189

(C) CONVERTER 2021

www.converter-magazine.info 


\begin{tabular}{c|c}
\hline$z$ & the inventory factor $=q / y(p, \theta)$ \\
\hline$\Pi_{C}$ & the whole channel's profit in the centralized supply chain \\
\hline$\Pi_{d, M}$ & the manufacturer's profit in the decentralized supply chain \\
\hline$\Pi_{d, R}$ & the retailer's profit in the decentralized supply chain \\
\hline
\end{tabular}

By Petruzzi and Dada ${ }^{47]}$, denote $z=q / y(p, \theta)$ as the stocking factor of inventory, and, $E[\min \{D, q\}]=$ $y(p, \theta)(z-\Lambda(z))$ with

$$
\Lambda(z)=\int_{A}^{z}(z-x) f(x) d x
$$

Eq. (1) allows us to represent profit functions more conveniently.

\subsection{Decisions in centralized supply chain}

In the centralized case, both the manufacturer and the retailer can be regarded as a joint community, which is an ideal state, and they aim to obtain maximum profits. Total profits of the centralized supply chain can be written as

$$
\begin{aligned}
\Pi_{c}(p, q, \theta) & =p E[\min \{D, q\}]-c q-I \theta^{2}, \\
= & p[y(p, \theta)(z-\Lambda(z))]-c q-I \theta^{2} . \#(2)
\end{aligned}
$$

Substituting $q=z y(p, \theta)$ into Eq. (2), the profit function can be rewritten as

$$
\begin{gathered}
\Pi_{c}(p, z, \theta)=p[y(p, \theta)(z-\Lambda(z))]-c z y(p, \theta)-I \theta^{2}, \\
=a p^{1-\alpha} \theta^{\beta}(z-\Lambda(z))-a c z p^{-\alpha} \theta^{\beta}-I \theta^{2} . \#(3)
\end{gathered}
$$

In the above newsvendor model, to maximize total profits, the decision-makers need to choose optimal solutions $\left(p_{c}^{*}, z_{c}^{*}, \theta_{c}^{*}\right)$. Specifically, we first determine the optimal retail price $p_{c}^{*}$ and production green-level $\theta_{c}^{*}$ for any given $z$ and then maximize $\prod_{c}\left[p_{c}^{*}(z), z, \theta_{c}^{*}(z)\right]$ over $z$ to find $z_{c}^{*}$.

Theorem 1 In the centralized supply chain under multiplicative random demand model, the unique optimal decisions are given in the following for any $z$ in $A \leq z \leq B$,

$$
\begin{gathered}
p_{c}^{*}(z)=\frac{c \alpha z}{(\alpha-1)(z-\Lambda(z))} \cdot \#(4) \\
\theta_{c}^{*}(z)=\left[\frac{\beta a(\alpha-1)^{\alpha-1}}{2 I c^{\alpha-1} \alpha^{\alpha}} \cdot \frac{(z-\Lambda(z))^{\alpha}}{z^{\alpha-1}}\right]^{\frac{1}{2-\beta}} . \#(5)
\end{gathered}
$$

and, If $g(z)>\frac{1}{\alpha}$, then the optimal stocking factor $z=z_{c}^{*}$ which maximizes $\prod_{c}\left[p_{c}^{*}(z), z, \theta_{c}^{*}(z)\right]$ is uniquely determined by

Moreover, if $\beta<2$, then there exists non-negative profits

$$
z_{c}^{*}-\Lambda\left(z_{c}^{*}\right)=\alpha\left(z_{c}^{*} F\left(z_{c}^{*}\right)-\Lambda\left(z_{c}^{*}\right)\right)
$$

$$
\Pi_{c}\left(p_{c}^{*}(z), z, \theta_{c}^{*}(z)\right)=\frac{I(2-\beta)}{\beta}\left(\theta_{c}^{*}\right)^{2} . \#(7)
$$

All proofs are in the appendix.

In the theorem, we find that the stocking factor $z_{c}^{*}$ only depends on price elasticity index $\alpha$ and cumulative distribution function $F(\cdot)$, but has nothing to do with $\beta, c$ and $I$. Besides, the retail price $p_{c}^{*}$ depends on $c, \alpha$ and $z$. Limiting conditions of Theorem 1 are relative mild, only $g(z)>\frac{1}{\alpha}$ is required, and there are no restrictions on other parameters. This condition can be satisfied by distribution functions such as uniform and normal. Now, we will investigate how the parameters, say $a, c, I, \alpha, \beta$, influence on each variables and on the whole channel's performance.

ISSN: 0010-8189 
Proposition 1 In the centralized channel, we have the following properties:

(1) Stocking factor $z_{c}^{*}$ only depends on and decreases in $\alpha$;

(2) Optimal retail price $p_{c}^{*}$ is increasing in $c$ and decreasing in $\alpha$;

(3) Green-level $\theta_{c}^{*}$ is increasing in a and $\beta$, and decreasing in $c$ and I;

(4) Total profits $\Pi_{c}^{*} i$ increasing in a, and decreasing in $c$ and I.

\subsection{Decisions in decentralized supply chain}

In this section, we will study the performance of a decentralized supply chain under multiplicative demand model. In order to maximize the profits, the manufacturer firstly determines production quantity, wholesale price and green-level of green products. After observing the $(q, \omega, \theta)$ set by the manufacturer, the retailer determines retail price to maximize his own profits. In Figure 1, the structure of our supply chain is showed.

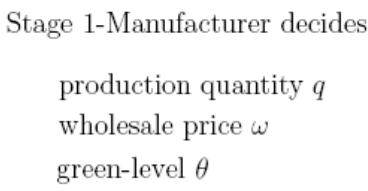

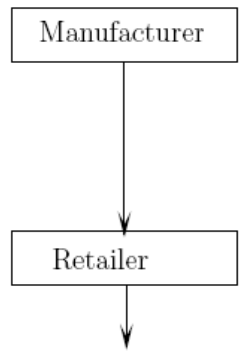

Figure 1: Two stage supply chain structure

\section{Decisions of the Retailer}

The retailer's profit function is as follows:

$$
\begin{aligned}
\Pi_{d, R}(p / z, \omega, \theta) & =(p-\omega) E[\min [D, q\}] \\
= & (p-\omega) y(p, \theta)(z-\Lambda(z)) \#(8) \\
& =(p-\omega) a p^{-\alpha} \theta^{\beta}(z-\Lambda(z)) .
\end{aligned}
$$

Following the procedure of solving a newsvendor problem, we can solve the optimal problem of Eq. (8) in a similar way. For any given $(z, \omega, \theta)$ by the manufacturer, the retailer decides retail price $p_{d}$ which satisfies the first-order condition, that is, $\frac{\partial \prod_{d, R}}{\partial p}=0$. Then

$$
p_{d}=\frac{\alpha}{\alpha-1} \omega_{d}
$$

Note that $\frac{\partial \Pi_{d, R}}{\partial p}=a \theta^{\beta}(z-\Lambda(z))\left[p^{-\alpha}+(p-\omega)(-\alpha) p^{-\alpha-1}\right]$.The $\frac{\partial^{2} \Pi_{d, R}}{\partial p^{2}}=a(-\alpha) \theta^{\beta}(z-\Lambda(z)) p^{-\alpha-2}[2 p+(p-$ $\omega)(-\alpha-1)]$, by substituting Eq.(9) into the last factor, we have $\frac{\partial^{2} \Pi_{d, R}}{\partial p^{2}}=a(-\alpha) \theta^{\beta}(z-\Lambda(z)) p^{-\alpha-2} \omega<$ 0,implying that Eq. (9) is the optimal retail price of retailer. Next, we will state the relationship between optimal retail price and wholesale price in the following proposition.

Proposition 2 In decentralized green supply chain under multiplicative random demand model, the optimal retail price of retailer depends heavily on his wholesale price given by manufacturer, i.e. $p_{d}=\frac{\alpha}{\alpha-1} \omega_{d}$. Furthermore, retail price is always larger than wholesale price, i.e. $p_{d}>\omega_{d}$, so that the retailer can make non-negative profits.

Decisions of the Manufacturer

Based on the retailer's selection of a certain retail price $p_{d}$ according to Eq. (9) for some given $(z, \omega, \theta)$, the

ISSN: 0010-8189 
manufacturer makes a sequential decision to get the optimal solutions $\left(z_{d}^{*}, \omega_{d}^{*}, \theta_{d}^{*}\right)$. The manufacturer's profit function is

$$
\begin{aligned}
\Pi_{d, M}(z, \omega, \theta / p) & =\omega E[\min \{D, q\}]-c q-I \theta^{2} \\
= & \omega[y(p, \theta)(z-\Lambda(z))]-c q-I \theta^{2} \#(10) \\
& =\omega a p^{-\alpha} \theta^{\beta}(z-\Lambda(z))-a c z p^{-\alpha} \theta^{\beta}-I \theta^{2} .
\end{aligned}
$$

Substituting Eq. (9) into Eq. (10), we have

$$
\begin{aligned}
\Pi_{d, M}(z, \omega, \theta / \mathrm{p}) & =\omega a\left(\frac{\alpha}{\alpha-1} \omega\right)^{-\alpha} \theta^{\beta}(z-\Lambda(z))-a c z\left(\frac{\alpha}{\alpha-1} \omega\right)^{-\alpha} \theta^{\beta}-I \theta^{2} \\
= & a\left(\frac{\alpha}{\alpha-1}\right)^{-\alpha}(z-\Lambda(z)) \theta^{\beta} \omega^{1-\alpha}-a c z\left(\frac{\alpha}{\alpha-1}\right)^{-\alpha} \theta^{\beta} \omega^{-\alpha}-I \theta^{2} . \#(11)
\end{aligned}
$$

Theorem 2 In decentralized green supply chain under multiplicative random demand model, the unique optimal decisions are as follows with $A \leq z \leq B$ :

$$
\begin{gathered}
p_{d}^{*}(z)=\frac{c \alpha^{2} z}{(\alpha-1)^{2}(z-\Lambda(z))} . \# \#(12) \\
\omega_{d}^{*}(z)=\frac{c \alpha z}{(\alpha-1)(z-\Lambda(z))} . \# \#(13) \\
\theta_{d}^{*}(z)=\left[\frac{\beta a(\alpha-1)^{2 \alpha-1}}{2 I c^{\alpha-1} \alpha^{2 \alpha}} \cdot \frac{(z-\Lambda(z))^{\alpha}}{z^{\alpha-1}}\right]^{\frac{1}{2-\beta}} . \# \#(14)
\end{gathered}
$$

and, if $g(z)>\frac{1}{\alpha}$, then the optimal stocking factor $z=z_{d}^{*}$ which maximizes the manufacturer's profit $\Pi_{d, M}\left[z, \omega_{d}^{*}(z), \theta_{d}^{*}(z) / p_{d}^{*}(z)\right]$ is uniquely determined by

$$
z_{d}^{*}-\Lambda\left(z_{d}^{*}\right)=\alpha\left(z_{d}^{*} F\left(z_{d}^{*}\right)-\Lambda\left(z_{d}^{*}\right)\right)
$$

If $\beta<2$, then there exists non-negative profits of both the manufacturer and the retailer:

$$
\Pi_{d, M}\left(z, \omega_{d}^{*}(z), \theta_{d}^{*}(z) / p_{d}^{*}(z)\right)=\frac{I(2-\beta)}{\beta}\left(\theta_{d}^{*}\right)^{2} . \#(16)
$$

and

$$
\Pi_{d, R}\left(p_{d}^{*}(z) / z, \omega_{d}^{*}(z), \theta_{d}^{*}(z)\right)=\frac{2 I \alpha}{\beta(\alpha-1)}\left(\theta_{d}^{*}\right)^{2} . \#(17)
$$

The following results are carried out by a similar procedure comparing to Proposition 1, so we omit the detailed proof.

Proposition 3 In decentralized channel, we have the following properties:

(1) Stocking factor $z_{d}^{*}$ only depends on and decreases in $\alpha$;

(2) Optimal retail price $p_{d}^{*}$ and wholesale price $\omega_{d}^{*}$ are increasing in $c$ and decreasing in $\alpha$;

(3) Green-level $\theta_{d}^{*}$ is increasing in a and $\beta$, and decreasing in $c$ and I;

(4) Manufacturer's profit $\Pi_{d, M}^{*}$ is increasing in a, and decreasing in $c$ and I;

(5) retailer's profit $\Pi_{d, R}^{*}$ is increasing in a and $\beta$, and decreasing in $c$ and $I$.

Now, we aim to calculate the distribution of total profits in the decentralized channel, that is, how total profits obtained by each member. By Eqs. (16) and (17), let $\gamma$ be profit sharing of retailer in the decentralized channel, denoted as

$$
\begin{gathered}
\gamma=\frac{\Pi_{d, R}^{*}}{\Pi_{d, M}^{*}+\Pi_{d, R}^{*}} \\
=\frac{2 \alpha}{(2-\beta)(\alpha-1)+2 \alpha} . \#(18)
\end{gathered}
$$

ISSN: 0010-8189 
Proposition 4 Retailer's share of total channel's profit $\gamma$ in the decentralized channel under multiplicative random demand model has the following properties:

(1) For a given $\beta, \gamma$ is decreasing in $\alpha$; and for a given $\alpha, \gamma$ is increasing in $\beta$;

(2) The limitation ofy reaches $100 \%$ in one or both the following two conditions: either $\alpha \rightarrow 1$ or $\beta \rightarrow 2$;

(3) When $\alpha \rightarrow \infty$, the limitation of $\gamma$ reaches $\frac{2}{4-\beta}$, and can always exceed $50 \%$.

In Proposition 4 Part (1), products with higher price elasticity, lead to more profits to the manufacturer rather than the retailer; products with higher green-level elasticity, are more beneficial to the retailer. Part (2) shows that the retailer can obtain total channel's profits in one or both the following two cases: either $\alpha$ is very low, namely, $\alpha \rightarrow 1$; or $\beta$ is very high, namely, $\beta \rightarrow 2$. Part (3) shows that the retailer can always obtain more than half of total channel's profits.

\section{Comparison of Decentralized and Centralized Supply Chain}

In this section, we will compare and analyze the relationship between optimal stocking factor, retail price, greenlevel and production quantity under decentralized and centralized decisions. Moreover, how the two parameters $\alpha$ and $\beta$ influence on variables' deviations is described. Under the equilibrium state, the following propositions show that comparison of each variables in decentralized and centralized channels is clear and concise under multiplicative random demand model. We follow the definitions and notations by Wang et al. $\left(2004^{[48]}\right)$. Although our model is different from Wangs', the results have many similarities.

Proposition 5Under multiplicative random demand model, the optimal stocking factor in the decentralized channel is equivalent to that in centralized channel, i.e. $z_{d}^{*}=z_{c}^{*}$.

Denote $\Delta_{p} \equiv \frac{p_{d}^{*}-p_{c}^{*}}{p_{c}^{*}}=\frac{1}{\alpha-1}>0$ as the percentage deviation of retail price.

Proposition 6 Under multiplicative random demand model.

(1) The optimal retail price in decentralized channel and centralized channel has the relationship $p_{d}^{*}=\frac{\alpha}{\alpha-1} p_{c}^{*}$;

(2) The optimal price in decentralized channel is always higher than that in centralized channel, i.e. $p_{d}^{*}>p_{c}^{*}$;

(3) $p_{d}^{*} / p_{c}^{*}$ only depends on and decreases in $\alpha$;

(4) $\Delta_{p}$ depends on and decreases in $\alpha$. Specifically, $\Delta_{p}$ decreases from $\infty$ to 0 with $\alpha$ increases from 1 to $\infty$, implying that with increase of the price-elastic index $\alpha$, retail price in the decentralized channel is close to the centralized one.

Corollary 1 The optimal wholesale price in the decentralized channel is always equivalent to the optimal retail price in the centralized channel, i.e. $\omega_{d}^{*}=p_{c}^{*}$.The decentralized supply chain can not be coordinated.

Denote $\Delta_{\theta} \equiv \frac{\theta_{d}^{*}-\theta_{c}^{*}}{\theta_{c}^{*}}=\left[\frac{\alpha-1}{\alpha}\right]^{\frac{\alpha}{2-\beta}}-1<0$ as the percentage deviation of production green-level.

Proposition 7 Under multiplicative random demand model.

(1) The optimal production green-level in decentralized channel and centralized channel has the relationship $\theta_{d}^{*}=\left[\frac{\alpha-1}{\alpha}\right]^{\frac{\alpha}{2-\beta}} \theta_{c}^{*}$

(2) The optimal production green-level in decentralized channel is always lower than that in centralized channel, i.e. $\theta_{d^{*}}<\theta_{c}^{*}$;

(3) $\theta_{d}^{*} / \theta_{c}^{*}$ depends on both $\alpha$ and $\beta$. Specifically, for any given $\beta, \theta_{d}^{*} / \theta_{c}^{*}$ is increasing in $\alpha$, and for anygiven $\alpha, \theta_{d}^{*} / \theta_{c}^{*}$ is decreasing in $\beta$;

ISSN: 0010-8189 
(4) $\left|\Delta_{\theta}\right|$, the absolute value of $\Delta_{\theta}$ decreases in price-elastic index $\alpha$ and increases in green-level-elastic index $\beta$. Specifically, for any given $\beta,\left|\Delta_{\theta}\right|$ decreases from $1-e^{\frac{-1}{2-\beta}}$ with $\alpha$ increases from 1 to $\infty$; and for any given $\alpha,\left|\Delta_{\theta}\right|$ increases from $1-\left[\frac{\alpha-1}{\alpha}\right]^{\frac{\alpha}{2}}$ to 1 with $\beta$ increases from 0 to 2 .

Denote $\Delta_{q} \equiv \frac{q_{d}^{*}-q_{c}^{*}}{q_{c}^{*}}=\left[\frac{\alpha-1}{\alpha}\right]^{\frac{2 \alpha}{2-\beta}}-1<0$ as the percentage deviation of production quantity.

Proposition 8 Under the multiplicative random demand model,

(1) The relationship of the optimal production quantity between the centralized channel and the decentralized channel is $q_{d}^{*}=\left[\frac{\alpha-1}{\alpha}\right]^{\alpha+\frac{\alpha \beta}{2-\beta}} q_{c}^{*}$;

(2) The optimal production quantity in a decentralized channel is always lower than that in the centralized channel, i.e. $q_{d}^{*}<q_{c}^{*}$;

(3) $q_{d}^{*} / q_{c}^{*}$ depends on both $\alpha$ and $\beta$. Specifically, for any given $\beta, q_{d}^{*} / q_{c}^{*}$ is increasing in $\alpha$; and for any given $\alpha, q_{d}^{*} / q_{c}^{*}$ is decreasing in $\beta$,

(4) $\left|\Delta_{q}\right|$, the absolute value of $\Delta_{q}$, decreases in price-elastic index $\alpha$ and increases in green-level index $\beta$. Specifically, for any given $\beta,\left|\Delta_{q}\right|$ decreases from 1 to $1-e^{\frac{-2}{2-\beta}}$ with $\alpha$ increases from 1 to $\infty$; and for any given $\alpha,\left|\Delta_{q}\right|$ increases from $1-\left[\frac{\alpha-1}{\alpha}\right]^{\alpha}$ to 1 with $\beta$ increases from 0 to 2 .

Next, we will discuss how the parameters $\alpha$ and $\beta$ influence on performance of centralized and decentralized channel profits. Denote $\Delta_{\Pi}$ as the percentage profit loss of decentralized channel, comparing to that of centralized channel. By Eq. (37), let

$$
\Delta_{\Pi}=\frac{\Pi_{c}^{*}-\Pi_{d}^{*}}{\Pi_{c}^{*}} \cdot 100 \% \# \#(19)
$$

Proposition 9 Under multiplicative random demand model.

(1) The total profits in centralized channel and decentralized channel has the relationship $\Pi_{d}^{*}=\left\{\left[\frac{\alpha-1}{\alpha}\right]^{\frac{2 \alpha}{2-\beta}}+\frac{2}{2-\beta}\left[\frac{\alpha-1}{\alpha}\right]^{\frac{2 \alpha}{2-\beta}-1}\right\} \cdot \Pi_{c}^{*} ;$

(2) The percentage profit loss is the function of $\alpha$ and $\beta$, i.e. $\Delta_{\Pi}=\left\{1-\left[\frac{\alpha-1}{\alpha}\right]^{\frac{2 \alpha}{2-\beta}}-\frac{2}{2-\beta}\left[\frac{\alpha-1}{\alpha}\right]^{\frac{2 \alpha}{2-\beta}-1}\right\} \cdot 100 \%$;

(3) For any $0<\beta<2$, $\lim _{\alpha \rightarrow 1} \Delta_{\Pi}=1$; and $\lim _{\alpha \rightarrow \infty} \Delta_{\Pi}=1-\frac{4-\beta}{2-\beta} e^{\frac{-2}{2-\beta}}$, which is increasing in $\beta$.

(4) For any $\alpha>1, \lim _{\beta \rightarrow 2} \Delta_{\Pi}=1$

From the above propositions, it can be seen that compared with centralized decision-making in decentralized channel, retail price is higher, green-level is lower, output is lower, and supply chain profit is lower. It is interesting that $\Delta_{p}$ only depends on price elasticity index $\alpha$, while $\Delta_{\theta}, \Delta_{q}$ and $\Delta_{\Pi}$ depends on price elasticity index $\alpha$ and green-level elasticity index $\beta$. It is also can be seen that the decentralized decisions approach the centralized ones as $\alpha$ increases or $\beta$ decreases. When price elasticity index approaches 1 or green-level elasticity index $\beta$ approaches 2 , the total profit of decentralized channel approaches 0 . The performance of decentralized channel reaches the limitation $1-\frac{4-\beta}{2-\beta} e^{\frac{-2}{2-\beta}}$ when the price elasticity index is very high, that is, $\alpha \rightarrow \infty$. This limitation value only relies on and increases in the parameter $\beta$. In particular, if the production green-level elasticity index $\beta=0$, then $\Delta_{\Pi}$ is increasing in $\alpha$, and $\lim _{\alpha \rightarrow \infty} \Delta_{\Pi}=1-\frac{2}{e} \approx 26.4 \%$, which is consistent to the result of Wang et al. $^{[48]}$.

ISSN: 0010-8189 


\section{Numerical Experiments}

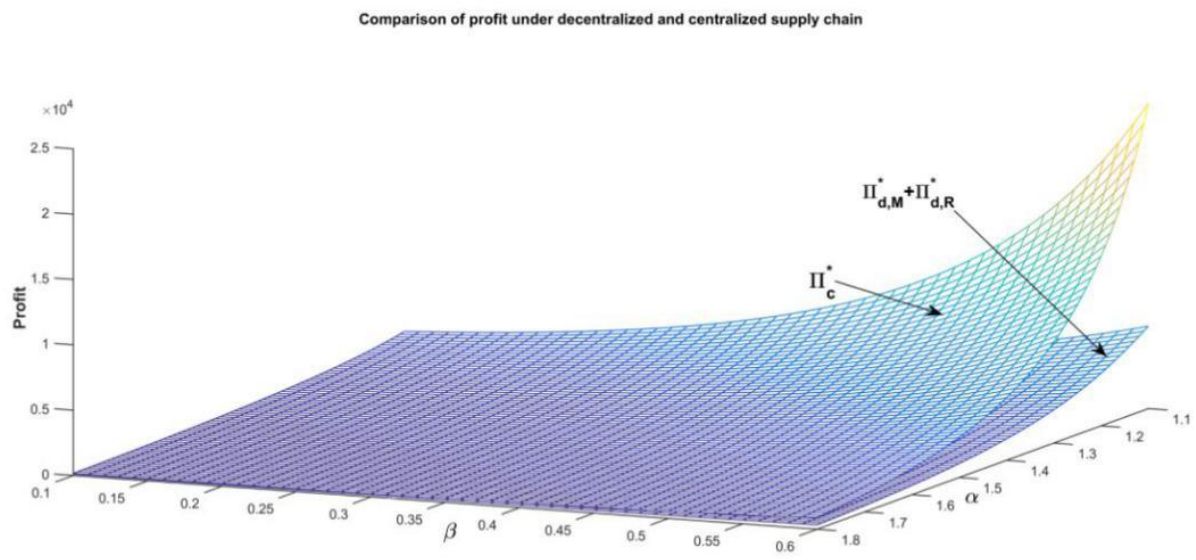

Fig 2: Comparison of total profit under decentralized and centralized supply chain

In order to test and verify our models, we use hypothesis data sets to evaluate how the parameters influence on optimal decisions and on total profits. We consider the uniform distributions for random variable $\varepsilon$ on $[A, B]$, where $A=10$ and $B=50$. Before the simulations, according to the recent reference Zhu et al. ${ }^{[49]}$, we set the important parameters as follows: $c=5, a=80$ and $I=0.58$.

Firstly, we discuss the impact of $\alpha$ and $\beta$ on total profits in different channels. As can be seen in Figure 2, with the decreasing of $\alpha$ and increasing of $\beta$, the total profits in both channels have an increasing trend. At the same time, we can see that the total profits of centralized channel are always higher than that in decentralized channel for any given $\alpha$ and $\beta$. Insight 1 is followed.

Insight 1. Whether in centralized or decentralized paradigm, the optimal total profit of the supply chain increases with decreasing price elasticity, or higher green level elasticity.

The intuition behind Insight 1 is that the supply chain has more profitability in the face of less price elasticity. The more profitable the supply chain is for products whose prices have less impact on demand. As for green-level, the greater the elasticity, the stronger profitability of the supply chain is. The green-level of green products has a great impact on product demand. Those green products with high elasticity will enhance the profitability of enterprises.
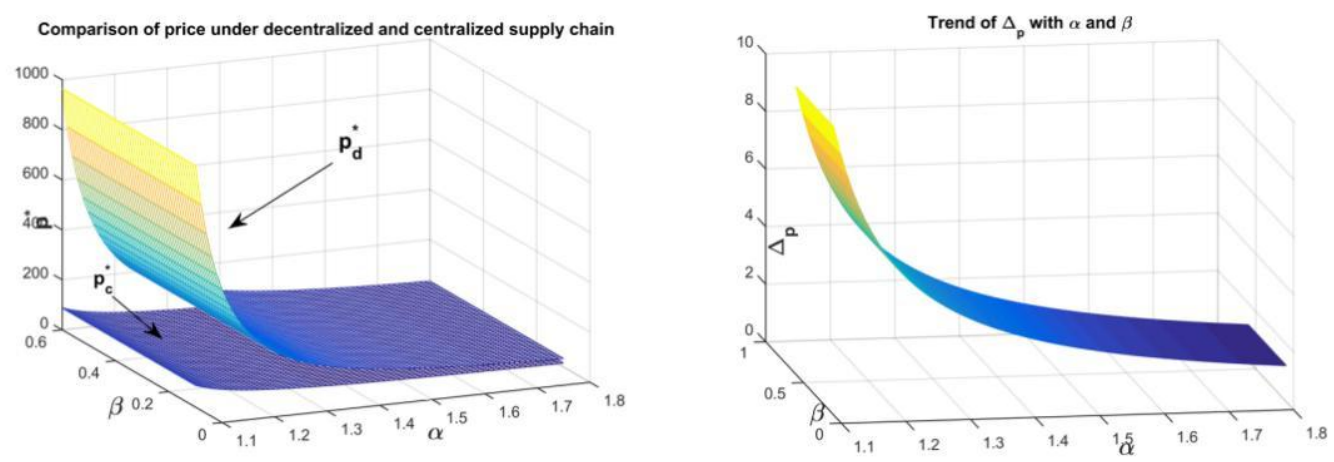

Fig 3: Comparison of price under decentralized and centralized supply chain, together with the trend of $\Delta_{p}$ with $\alpha$ and $\beta$

Next, we will study how the parameters $\alpha$ and $\beta$ influence the optimal retail price. As shown in Figure 3 , the optimal retail price only depend on $\alpha$, with the decrease of $\alpha$, the optimal retail price represents a sharp increasing trend in the decentralized channel, while that of centralized channel has a slow increasing trend. Then Proposition 6 holds true.

ISSN: 0010-8189 

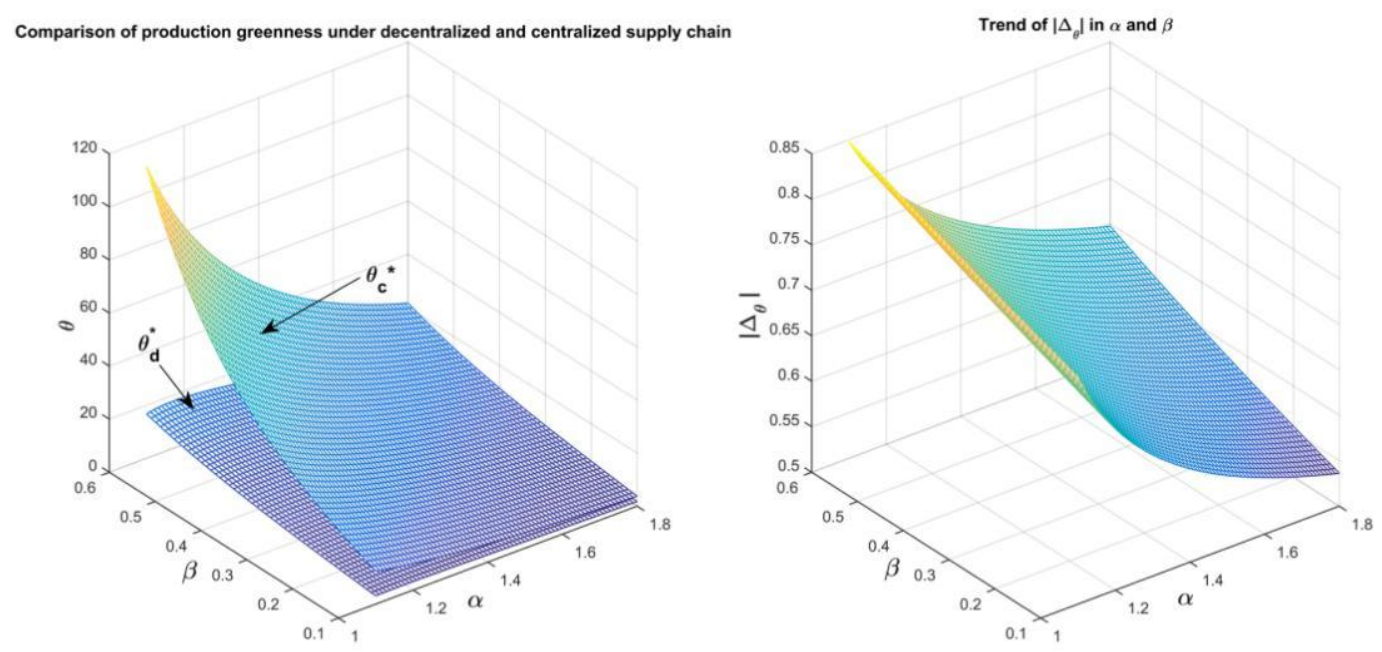

Fig 4: Comparison of production green-level under decentralized and centralized supply chain, together with the trend of $\left|\Delta_{\theta}\right|$ in $\alpha$ and $\beta$

Figure 4 also reveals that the optimal green-level in the centralized channel is always higher than that in the decentralized channel. At the same time, it can be seen that the products with smaller price elasticity and larger green-level elasticity have greater $\Delta_{\theta}$, then Proposition 5.3 holds true. These observations are summarized in the sight below.
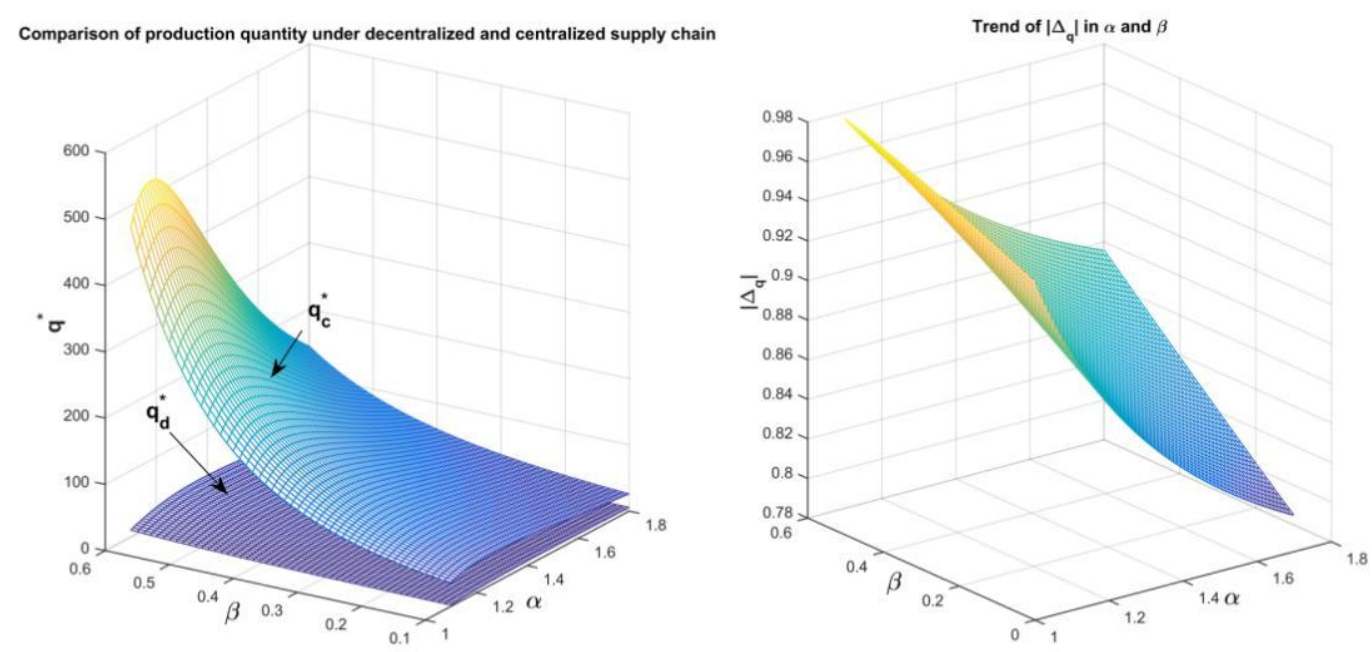

Fig 5: Comparison of production quantity under decentralized and centralized supply chain, together with the trend of $\left|\Delta_{q}\right|$ in $\alpha$ and $\beta$

Insight 2. The optimal price is greatly affected by the price elasticity, and it decrease as the elasticity increases.

The greater the price elasticity of the product, it means that changes in product price have greater impact on the demand for product. Enterprises should reduce price to gain more market share, and increase corporate profits. In addition, the centralized decision paradigm decreases the product price, the price gap increases with decreasing price elasticity.

ISSN: 0010-8189 
Insight 3. Whether in centralized or decentralized paradigm, the optimal green-level of the supply chain increases with increasing green-level elasticity, or decreasing price elasticity.

Higher green-level elasticity or lower price elasticity will make the enterprise have a strong motivation to improve the green-level of green products. When price elasticity is greater, price has a greater impact on demand, and the green-level of the green product can be appropriately reduced. When the green-level elasticity is greater, companies must continue to increase the green-level of product, improve the competitiveness of the green product, and obtain more profits.It can be seen from Figure 5 that the optimal production quantity curve of the centralized channel has a larger slope than that of the decentralized channel, which shows that the production quantity of the centralized channel is higher than that of the decentralized channel. At the same time, it can be seen that the products with smaller price elasticity and larger green-level elasticity have greater $\Delta_{q}$, then Proposition 5.4 holds true.

\section{Conclusion}

Based on random demand (multiplicative cases), newsvendor models are established to investigate the green supply chain. We fully studied the optimal decisions of both manufacturer and retailer under decentralized and centralized decisions, discussed the impact of various parameters on optimal decisions. Since the demand for green products is random, the optimal decision of the supply chain is affected by the random factor. From the mathematical derivation, we can see that if the random factor is determined, the optimal decision can get the closed-loop optimal result.

A number of observations and insights were obtained through model analysis and numerical studies. The increase in price elasticity will reduce the stocking factor, lower the selling price of the green product, and reduce enterprise's profits. It will also reduce the retailer's profit sharing in the green supply chain. Specifically, for green products with high price elasticity, the manufacturer should reduce inventories, and the retailer should lower their prices to maximize profits. In addition, the high price elasticity will weaken the profitability of the green supply chain and will further reduce the retailer's share in the supply chain. On the other hand, the increase in green-level elasticity will increase the green-level of the product, improve the profitability of the entire green supply chain, and increase the retailer's share in the supply chain. Specifically, for green products with high green-level elasticity, the manufacturer should take improving the green-level of the product as the main decision to increase the profitability of the supply chain. However, the improvement of green-level of products requires the increase of R\&D costs, which reduces the proportion of the manufacturer in the supply chain, which is more beneficial to the retailer. Our work fills the gaps in the literature to solve the optimal decision-making problem of the green supply chain under random demand. For green supply chain practitioners, our modeling framework and methods provide a feasible method to specify inventory, pricing, and green production decision-making strategies in a random demand environment based on input information about market structure and demand functions.

Considering the limitations of this paper, some assumptions in the model can be relaxed and further verified, such as the assumption of multiplicative demand, no salvage value and no disposal cost, and the green R\&D investment quadratic function, etc. In addition, here are a few directions we want to explore further. For example, although the multiplicative demand hypothesis is widely adopted in economic models, it is necessary for us to study the newsvendor model in the form of other demand functions in future research. We will further study this model of complex supply chains such as dual-channel green supply chains.

\section{Appendix}

Proof of Theorem 1: By Eq. (3), $\frac{\partial \Pi_{c}(p, z, \theta)}{\partial p}=a(1-\alpha) p^{-\alpha} \theta^{\beta}(z-\Lambda(z))-a c z(-\alpha) p^{-\alpha-1} \theta^{\beta}$. Since $a p^{-\alpha} \theta^{\beta}>0$ for $0<p<\infty, \frac{\partial \Pi_{c}(p, z, \theta)}{\partial p}=0$ implies that $p_{c}^{*}(z)=\frac{c \alpha z}{(\alpha-1)(z-\Lambda(z))}$, which is Eq. (4). Also byEq. (3), $\frac{\partial \Pi_{c}(p, z, \theta)}{\partial \theta}=$ 
$a p^{1-\alpha} \beta \theta^{\beta-1}(z-\Lambda(z))-a c z p^{-\alpha} \beta \theta^{\beta-1}-2 I \theta$. Since $p^{-\alpha} \theta^{\beta-1}>0, \frac{\partial \Pi_{c}(p, z, \theta)}{\partial \theta}=0$ impliesthat $2 I \theta^{2-\beta} p^{\alpha}=$ $a \beta p(z-\Lambda(z))-a c z \beta$. By Eq. (4), we have $p_{c}^{*}(z-\Lambda(z))=\frac{c \alpha z}{\alpha-1}$. Then

$$
\theta^{2-\beta}\left(p_{c}^{*}\right)^{\alpha}=\frac{a c \beta z}{2 I(\alpha-1)}(20)
$$

and hence

$$
\theta_{c}(z)=\left[\frac{a c \beta z}{2 I(\alpha-1)\left(p_{c}^{*}\right)^{\alpha}}\right]^{\frac{1}{2-\beta}} \#(21)
$$

by substituting Eq. (4) into Eq. (21) we have Eq. (5). Before we substitute Eq. (4) and (5) into Eq. (3) to simplify $\Pi_{c}(p, z, \theta)$, first we denote a constant $g$ as $g=\frac{a c \beta}{2 I(\alpha-1)}$. By Eq. (20), we get

$$
\left(p_{c}^{*}\right)^{-\alpha} \theta^{\beta}=\frac{\theta^{2}}{g z} \#(22)
$$

and substituting Eq. (22) into Eq. (3), we have that

$$
\begin{aligned}
\Pi_{c}\left(p_{c}^{*}(z), z, \theta_{c}^{*}(z)\right)= & a p_{c}^{*}(z-\Lambda(z)) \frac{\left(\theta_{c}^{*}\right)^{2}}{g z}-a c z \frac{\left(\theta_{c}^{*}\right)^{2}}{g z}-I\left(\theta_{c}^{*}\right)^{2} \\
= & {\left[\frac{a p_{c}^{*}(z-\Lambda(z))}{g z}-\frac{a c}{g}-I\right]\left(\theta_{c}^{*}\right)^{2} } \\
= & {\left[\frac{a \frac{c \alpha z}{\alpha-1}}{g z}-\frac{a c}{g}-I\right]\left(\theta_{c}^{*}\right)^{2}(23) } \\
= & \left.\frac{a c}{g(\alpha-1)}-I\right]\left(\theta_{c}^{*}\right)^{2} \\
& =\left[\frac{a c}{\frac{a c \beta}{2 I}}-I\right]\left(\theta_{c}^{*}\right)^{2} \\
& =\frac{I(2-\beta)}{\beta}\left(\theta_{c}^{*}\right)^{2}
\end{aligned}
$$

In the end, we aim to find the optimal stocking factor $z_{c}^{*}$. Applying the chain rule on Eq. (23), the first-order condition gives us

$$
\frac{\partial \Pi_{c}\left(p_{c}^{*}(z), z, \theta_{c}^{*}(z)\right)}{\partial z}=\frac{2 I(2-\beta)}{\beta} \theta_{c}^{*} \frac{d \theta_{c}^{*}}{d z} \#(24)
$$

Since $\frac{2 I(2-\beta)}{\beta} \theta_{c}^{*}>0$, to solve $\frac{\partial \Pi_{c}\left(p_{c}^{*}(z), z, \theta_{c}^{*}(z)\right)}{\partial z}=0$ is equal to solve $\frac{d \theta_{c}^{*}}{d z}=0$. To simplify our calculations, let $m$ be a constant denoted as $m=\left[\frac{\beta a(\alpha-1)^{\alpha-1}}{2 I c^{\alpha-1} \alpha^{\alpha}}\right]^{\frac{1}{2-\beta}}$. So, Eq. (5) can be written as following:

$$
\theta_{c}^{*}=m(z-\Lambda(z))^{\frac{\alpha}{2-\beta}} z^{\frac{1-\alpha}{2-\beta}}
$$

Now

$$
\begin{aligned}
& \frac{d \theta_{c}^{*}}{d z}=m\left[\frac{\alpha}{2-\beta}(z-\Lambda(z))^{\frac{\alpha}{2-\beta}-1}(1-F(z)) z^{\frac{1-\alpha}{2-\beta}}+(z-\Lambda(z))^{\frac{\alpha}{2-\beta}} \frac{1-\alpha}{2-\beta} z^{\frac{1-\alpha}{2-\beta}-1}\right] \\
& =\frac{m}{2-\beta}(z-\Lambda(z))^{\frac{\alpha}{2-\beta}} z^{\frac{1-\alpha}{2-\beta}}\left[\alpha \frac{1-F(z)}{z-\Lambda(z)}+\frac{1-\alpha}{z}\right] \\
& =\frac{m}{2-\beta}(z-\Lambda(z))^{\frac{\alpha}{2-\beta}} z^{\frac{1-\alpha}{2-\beta}} \frac{\alpha z(1-F(z))+(1-\alpha)(z-\Lambda(z))}{z(z-\Lambda(z))} \\
& =\frac{m}{2-\beta}(z-\Lambda(z))^{\frac{\alpha}{2-\beta}} z^{\frac{1-\alpha}{2-\beta}} \frac{z-\Lambda(z)+\alpha(\Lambda(z)-z F(z))}{z(z-\Lambda(z))}
\end{aligned}
$$

ISSN: 0010-8189 
$=\frac{m}{2-\beta}(z-\Lambda(z))^{\frac{\alpha}{2-\beta}-1} z^{\frac{1-\alpha}{2-\beta}-1}[z-\Lambda(z)+\alpha(\Lambda(z)-z F(z))]$

Note that the first three factors in the above expression are always positive. The first-order condition requires the optimal $z_{c}^{*}$ satisfy

$$
z-\Lambda(z)+\alpha(\Lambda(z)-z F(z))=0, \#(26)
$$

which gives us Eq. (6). To verify the uniqueness of $z_{c}^{*}$, we need to prove that $\frac{\partial^{2} \Pi_{c}\left(p_{c}^{*}(z), z, \theta_{c}^{*}(z)\right)}{\partial z^{2}}<0$ in the case of $\frac{\partial \Pi_{c}\left(p_{c}^{*}(z), z, \theta_{c}^{*}(z)\right)}{\partial z}=0$ (or equivalently, in the case of $\frac{d \theta_{c}^{*}}{d z}=0$ ). Based on Eq. (24), we have

$$
\begin{gathered}
\frac{\partial^{2} \Pi_{c}\left(p_{c}^{*}(z), z, \theta_{c}^{*}(z)\right)}{\partial z^{2}}=\frac{2 I(2-\beta)}{\beta}\left[\left(\frac{d \theta_{c}^{*}}{d z}\right)^{2}+\theta_{c}^{*} \frac{d^{2} \theta_{c}^{*}}{d z^{2}}\right] \\
\begin{aligned}
\frac{\partial^{2} \Pi_{c}\left(p_{c}^{*}(z), z, \theta_{c}^{*}(z)\right)}{\partial z^{2}} & =\frac{2 I(2-\beta)}{\beta}\left[\left(\frac{d \theta_{c}^{*}}{d z}\right)^{2}+\theta_{c}^{*} \frac{d^{2} \theta_{c}^{*}}{d z^{2}}\right] \\
= & \frac{2 I(2-\beta)}{\beta} \theta_{c}^{*} \frac{d^{2} \theta_{c}^{*}}{d z^{2}} \#(27)
\end{aligned}
\end{gathered}
$$

Since $\frac{2 I(2-\beta)}{\beta} \theta_{c}^{*}>0$, to prove $\frac{\partial^{2} \Pi_{c}\left(p_{c}^{*}(z), z, \theta_{c}^{*}(z)\right)}{\partial z^{2}}<0$ is equal to prove $\frac{d^{2} \theta_{c}^{*}}{d z^{2}}<0$. Now,

$$
\begin{aligned}
\frac{d^{2} \theta_{c}^{*}}{d z^{2}}= & \frac{m}{2-\beta}\left\{\frac{d\left[(z-\Lambda(z))^{\frac{\alpha}{2-\beta}-1}\right]}{d z} \cdot z^{\frac{1-\alpha}{2-\beta}-1}[z-\Lambda(z)+\alpha(\Lambda(z)-z F(z))]\right. \\
& +(z-\Lambda(z))^{\frac{\alpha}{2-\beta}-1} \cdot \frac{d\left[z^{\frac{1-\alpha}{2-\beta}-1}\right]}{d z} \cdot[z-\Lambda(z)+\alpha(\Lambda(z)-z F(z))] \\
& \left.+(z-\Lambda(z))^{\frac{\alpha}{2-\beta}-1} z^{\frac{1-\alpha}{2-\beta}-1} \cdot \frac{d[z-\Lambda(z)+\alpha(\Lambda(z)-z F(z))]}{d z}\right\} . \quad \#(28)
\end{aligned}
$$

By Eq. (26), Eq. (28) can be further simplified as

$$
\begin{gathered}
\frac{d^{2} \theta_{c}^{*}}{d z^{2}}=(z-\Lambda(z))^{\frac{\alpha}{2-\beta}-1} z^{\frac{1-\alpha}{2-\beta}-1} \cdot \frac{d[z-\Lambda(z)+\alpha(\Lambda(z)-z F(z))]}{d z} \\
=\frac{m}{2-\beta}(z-\Lambda(z))^{\frac{\alpha}{2-\beta}-1} z^{\frac{1-\alpha}{2-\beta}-1}[1-F(z)+\alpha(F(z)-F(z)-z f(z))] \\
=\frac{m}{2-\beta}(z-\Lambda(z))^{\frac{\alpha}{2-\beta}-1} z^{\frac{1-a}{2-\beta}-1}[1-F(z)-\alpha g(z)] .
\end{gathered}
$$

It is easy to verify that the first three factors of the above equation are positive. Since $g(z)>\frac{1}{\alpha}$, we have $1-F(z)-\alpha g(z)<0$, and hence $\frac{d^{2} \theta_{c}^{*}}{d z^{2}}<0$.The proof is now completed.

Proof of Proposition 1: Part (1) By Eq. (6), $z=z_{c}^{*}$ can be seen as a function of $\alpha$. By first-order condition, we have

$$
\frac{d z}{d \alpha}=\frac{z F(z)-\Lambda(z)}{\bar{F}(z)-\alpha z f(z)} . \#(29)
$$

Note that $\frac{d[z F(z)-\Lambda(z)]}{d z}=z f(z)>0$ and $A F(A)-\Lambda(A)=0$. Then we have $z F(z)-\Lambda(z)>0$. In conjunction with the condition that $g(z)>\frac{1}{\alpha}$, we have $\frac{d z}{d \alpha}<0$

Part (2) Obviously, $p_{c}^{*}$ is increasing in $c$.

Next, we prove that $p_{c}^{*}$ is decreasing in $\alpha$. By Eq. (4), let $p_{c}^{*}=l_{1}(\alpha) \cdot l_{2}(\alpha)$, where $l_{1}(\alpha)=\frac{c}{1-\frac{1}{\alpha}}$ and $l_{2}(\alpha)=\frac{z}{z-\Lambda(z)}$. Clearly, $l_{1}(\alpha)$ is decreasing in $\alpha$. Now, we aim to prove that $l_{2}(\alpha)$ is decreasing in $\alpha$. Infact,

$$
\frac{d\left[l_{2}(\alpha)\right]}{d \alpha}=\frac{z F(z)-\Lambda(z)}{(z-\Lambda(z))^{2}} \cdot \frac{d z}{d \alpha} .
$$

ISSN: 0010-8189 
Together with Part (1), we have $\frac{d\left[l_{2}(\alpha)\right]}{d \alpha}<0$.

Part (3) It is easy to check the increasing or decreasing property of $\theta_{c}^{*}$ on $a$, cand $I$.

By Eq. (5), let $\left[\theta_{c}^{*}\right]^{2-\beta}=l_{3} \beta$, where $l_{3}=\frac{a(\alpha-1)^{\alpha-1}}{2 I c^{\alpha-1} \alpha^{\alpha}} \cdot \frac{(z-\Lambda(z))^{\alpha}}{z^{\alpha-1}}$ is a positive constant relative to $\beta$. By first-order condition, we have

$$
(2-\beta)\left[\theta_{c}^{*}\right]^{1-\beta} \frac{d \theta_{c}^{*}(\beta)}{d \beta}=l_{3}
$$

and this implies that $\frac{d \theta_{c}^{*}}{d \beta}>0$. So $\theta_{c}^{*}$ is increasing in $\beta$.

Part (4) Obviously, $\Pi_{c}^{*}$ is increasing in $a$ and decreasing in $c$. By Eq. (5), let, where $\theta_{c}^{*}=l_{4} I^{-\frac{1}{2-\beta}}$, where $l_{4}=\left[\frac{\beta a(\alpha-1)^{\alpha-1}}{2 c^{\alpha-1} \alpha^{\alpha}} \cdot \frac{(z-\Lambda(z))^{\alpha}}{z^{\alpha-1}}\right]^{\frac{1}{2-\beta}}$. This follows that $\Pi_{\mathrm{c}}^{*}(I)=\frac{(2-\beta)}{\beta}\left(l_{4}\right)^{2} I^{-\frac{2}{2-\beta}}=\frac{(2-\beta)}{\beta}\left(l_{4}\right)^{2} I^{-\frac{1}{2-\beta}}$. Byfirst-order condition, we have

This implies that $\Pi_{c}^{*}$ is decreasing in $I$.

$$
\frac{d \Pi_{c}^{*}}{d I}=-\left(l_{4}\right)^{2} I^{-\frac{\beta}{2-\beta}-1}<0 \#(31)
$$

Proof of Proposition 2: The conclusions are obvious by assuming $\alpha>1$.

Proof of Theorem 2: By Eq. (11), the first-order condition gives us

$$
\frac{\partial \Pi_{d, M}(z, \omega, \theta / p)}{\partial \omega}=a\left(\frac{\alpha}{\alpha-1}\right)^{-\alpha}(z-\Lambda(z)) \theta^{\beta}(1-\alpha) \omega^{-\alpha}-\operatorname{acz}\left(\frac{\alpha}{\alpha-1}\right)^{-\alpha} \theta^{\beta}(-\alpha) \omega^{-\alpha-1}=0
$$

so we have $\omega_{d}^{*}=\frac{c \alpha z}{(\alpha-1)(z-\Lambda(z))}$, which gives us Eq. (13). Substituting Eq. (13) into Eq. (9), we getEq. (12). With regard to $\theta$, also by Eq. (11), first-order condition shows that

$$
\frac{\partial \Pi_{d, M}(z, \omega, \theta / p)}{\partial \theta}=a\left(\frac{\alpha}{\alpha-1}\right)^{-\alpha}(z-\Lambda(z)) \beta \theta^{\beta-1} \omega^{1-\alpha}-2 I \theta-\operatorname{acz}\left(\frac{\alpha}{\alpha-1}\right)^{-\alpha} \beta \theta^{\beta-1} \omega^{-\alpha}=0
$$

By multiplying $\left(\frac{\alpha}{\alpha-1}\right)^{\alpha} \theta^{1-\beta} \omega^{\alpha}$ on each side of the above equation, we have

$$
2 I\left(\frac{\alpha}{\alpha-1}\right)^{\alpha} \theta^{2-\beta} \omega^{\alpha}=\beta a \omega(z-\Lambda(z))-\beta a c z \#(32)
$$

By Eq. (13), $\omega_{d}^{*}(z-\Lambda(z))=\frac{c \alpha z}{\alpha-1}$, we can further simplify Eq. (32) as

$$
\begin{aligned}
2 I\left(\frac{\alpha}{\alpha-1}\right)^{\alpha} \theta^{2-\beta}\left(\omega_{d}^{*}\right)^{\alpha} & =\beta a \frac{c \alpha z}{\alpha-1}-\beta a c z \\
= & \frac{\beta a c z}{\alpha-1} . \#(33)
\end{aligned}
$$

Therefore, $\theta^{2-\beta}=\frac{\beta a c z}{2 I(\alpha-1)}\left(\frac{\alpha-1}{\alpha}\right)^{\alpha}\left(\omega_{d}^{*}\right)^{-\alpha}$, in conjunction with Eq. (13), we have Eq. (14).

Now we are ready to simplify the manufacturer's profit $\Pi_{d, M}\left(z, \omega_{d}^{*}(z), \theta_{d}^{*}(z) / p_{d}^{*}(z)\right)$ and the retailer's profit $\Pi_{d, R}\left(p_{d}^{*}(z) / z, \omega_{d}^{*}(z), \theta_{d}^{*}(z)\right)$ by introducing a new notation $g$. Let $g=\frac{\beta a c}{2 I(\alpha-1)}$. Substituting Eq. (9) into Eq. (33), we have $2 I\left(p_{d}^{*}\right)^{\alpha}\left(\theta_{d}^{*}\right)^{2-\beta}=\frac{\beta a c z}{\alpha-1}$, that is,

$$
\left(p_{d}^{*}\right)^{-\alpha}\left(\theta_{d}^{*}\right)^{\beta}=\frac{\left(\theta_{d}^{*}\right)^{2}}{g z} \#(34)
$$

Substituting Eqs. (13) and (34) into Eq. (10), we have

$$
\begin{aligned}
\Pi_{d, M}\left(z, \omega_{d}^{*}(z), \theta_{d}^{*}(z) / p_{d}^{*}(z)\right) & =a \omega_{d}^{*}(z-\Lambda(z)) \frac{\left(\theta_{d}^{*}\right)^{2}}{g z}-a c z \frac{\left(\theta_{d}^{*}\right)^{2}}{g z}-I\left(\theta_{d}^{*}\right)^{2} \\
& =\left[\frac{a \omega_{d}^{*}(z-\Lambda(z))}{g z}-\frac{a c}{g}-I\right]\left(\theta_{d}^{*}\right)^{2} \\
= & {\left[\frac{a \frac{c \alpha z}{\alpha-1}}{g z}-\frac{a c}{g}-I\right]\left(\theta_{d}^{*}\right)^{2} \#(35) }
\end{aligned}
$$

ISSN: 0010-8189 
Substituting Eqs. (12), (13) and (34) into Eq. (8), we have

$$
\begin{aligned}
& =\left[\frac{a c}{g(\alpha-1)}-I\right]\left(\theta_{d}^{*}\right)^{2} \\
& =\left[\frac{a c}{\frac{\beta a c}{2 I}}-I\right]\left(\theta_{d}^{*}\right)^{2} \\
& =\frac{I(2-\beta)}{\beta}\left(\theta_{d}^{*}\right)^{2} .
\end{aligned}
$$

$$
\begin{aligned}
\Pi_{d, R}\left(p_{d}^{*}(z) / z, \omega_{d}^{*}(z), \theta_{d}^{*}(z)\right)=a\left(p_{d}^{*}\right. & \left.-\omega_{d}^{*}\right)(z-\Lambda(z)) \frac{\left(\theta_{d}^{*}\right)^{2}}{g z} \\
= & a\left[\frac{c \alpha^{2} z}{(\alpha-1)^{2}(z-\Lambda(z))}-\frac{c \alpha z}{(\alpha-1)(z-\Lambda(z))}\right](z-\Lambda(z)) \frac{\left(\theta_{d}^{*}\right)^{2}}{g z} \\
= & a\left[\frac{c \alpha^{2}}{(\alpha-1)^{2}}-\frac{c \alpha}{\alpha-1}\right] \frac{\left(\theta_{d}^{*}\right)^{2}}{g} \\
= & a \frac{c \alpha}{(\alpha-1)^{2}} \frac{\left(\theta_{d}^{*}\right)^{2}}{g} \quad \#(36) \\
& =\frac{a c \alpha}{(\alpha-1)^{2}} \cdot \frac{\left(\theta_{d}^{*}\right)^{2}}{\frac{\beta a c}{2 I(\alpha-1)}} \\
& =\frac{2 I \alpha}{\beta(\alpha-1)}\left(\theta_{d}^{*}\right)^{2}
\end{aligned}
$$

The proof of finding and proving the uniqueness of $z_{d}^{*}$ is completely consistent with the proof of proving the uniqueness of $z_{c}^{*}$ in Theorem 1, except that the value of $m$ is different (here, we let $m=\left[\frac{\beta a(\alpha-1)^{2 \alpha-1}}{2 I c^{\alpha-1} \alpha^{2 \alpha}}\right]^{\frac{1}{2-\beta}}$ ).

Proof of Proposition 4: Part (1) By Eq. (18), we have

$$
\frac{d \gamma}{d \alpha}=\frac{-2(2-\beta)}{[(2-\beta)(\alpha-1)+2 \alpha]^{2}}<0
$$

which implies that $\gamma$ is decreasing in $\alpha$; and we also have

$$
\frac{d \gamma}{d \beta}=\frac{2 \alpha(\alpha-1)}{[(2-\beta)(\alpha-1)+2 \alpha]^{2}}>0
$$

which indicates that $\gamma$ is increasing in $\beta$.

Part (2) By Eq. (18), we havelim $\lim _{\alpha \rightarrow 1} \gamma=1$. When $\beta \rightarrow 2$, we getlim $\lim _{\beta \rightarrow 2} \gamma=1$.

Part (3) By Eq. (18), we have $\lim _{\alpha \rightarrow \infty} \gamma=\frac{2}{4-\beta}$. Recall that $\gamma$ is decreasing in $\alpha$ and increasing in $\beta$. This generates a lower bound for $\gamma$ by letting $\alpha \rightarrow \infty$ and $\beta \rightarrow 0$. By Eq. (18), we havelim $\operatorname{lom}_{\alpha \rightarrow \infty \rightarrow 0} \gamma=\frac{1}{2}$.

Proof of Proposition 5: The conclusions are obvious by Eqs. (6) and (15). Compare Eqs. (4) and(13), and by using $z_{d}^{*}=z_{c}^{*}$, we have $\omega_{d}^{*}=p_{c}^{*}$.

Proof of Proposition 6: Part (1) By Proposition 5, we have $z_{d}^{*}=z_{c}^{*}$. In conjunction with Eqs. (4) and (12), we have that $p_{d}^{*}=\frac{\alpha}{\alpha-1} p_{c}^{*}$.

Part (2) It is easy to verify that $p_{d}^{*}>p_{c}^{*}$ from the fact that $\alpha>1$.

Part (3) To show that $\tilde{p} \equiv p_{d}^{*} / p_{c}^{*}=\frac{\alpha}{\alpha-1}$ is decreasing in $\alpha$ is equal to prove that the first derivation $\frac{d \tilde{p}}{d \alpha}<0$. In fact, $\frac{d \tilde{p}}{d \alpha}=\frac{-1}{(\alpha-1)^{2}}<0$.

Part (4) It is easy to verify the conclusion by $\alpha>1$.

Proof of Proposition 7: Part (1) Compare Eqs. (5) and (14), we have $\theta_{d}^{*}=\left[\frac{\alpha-1}{\alpha}\right]^{\frac{\alpha}{2-\beta}} \theta_{c}^{*}$ under the condition $z_{d}^{*}=z_{c}^{*}$. Part (2) It is easy to $\operatorname{check} \theta_{d}^{*}<\theta_{c}^{*}$ by the two conditions $\alpha>1$ and $0<\beta<2$.

ISSN: 0010-8189 
Part (3) To prove $\tilde{\theta} \equiv \theta_{d}^{*} / \theta_{c}^{*}=\left[\frac{\alpha-1}{\alpha}\right]^{\frac{\alpha}{2-\beta}}$ is increasing in $\alpha$ for any given $\beta$, we only need to prove $\frac{d \widetilde{\theta}}{d \alpha}>0$. In fact,

$$
\frac{d \tilde{\theta}}{d \alpha}=\frac{1}{2-\beta}\left[\frac{\alpha-1}{\alpha}\right]^{\frac{\alpha}{2-\beta}}\left[\frac{\alpha-1}{\alpha}+\frac{1}{\alpha-1}\right]
$$

The first two factors in $\frac{d \tilde{\theta}}{d \alpha}$ are positive by following $\alpha>1$ and $0<\beta<2$. The following discussion shows that the third factor, namely, $l(\alpha) \equiv \ln \frac{\alpha-1}{\alpha}+\frac{1}{\alpha-1}$ is also positive. This can be done as follows: $l^{\prime}(\alpha)=\frac{-1}{\alpha(\alpha-1)^{2}}<0$ and $\lim _{\alpha \rightarrow \infty} l(\alpha)=\ln \alpha+0=0$. Thus, $l(\alpha)>0$ for $\alpha>1$.

Next, we aim to prove $\tilde{\theta}$ is decreasing in $\beta$ for any given $\alpha$, or equivalently, to prove $\frac{d \widetilde{\theta}}{d \beta}<0$. Now the first derivation $\frac{d \widetilde{\theta}}{d \beta}=\frac{\alpha}{(2-\beta)^{2}}\left[\frac{\alpha-1}{\alpha}\right]^{\frac{\alpha}{2-\beta}} \ln \frac{\alpha-1}{\alpha}$. Clearly, the first two factors are positive. Since $\alpha>1$, we have $\frac{\alpha-1}{\alpha}<1$, and hence $\ln \frac{\alpha-1}{\alpha}<0$.

Part (4) For the convenience of analyze, let's write $|\Delta q|=1-L(\alpha, \beta)$, where $L(\alpha, \beta) \equiv\left[\frac{\alpha-1}{\alpha}\right]^{\frac{2 \alpha}{2-\beta}}$. Next we aim to show that $|\Delta q|$ is decreasing in $\alpha$, which implies that we only need to show $L(\alpha, \beta)$ is increasing in $\alpha$, say, $L_{\alpha}^{\prime}(\alpha, \beta)>0$ for $\alpha>1$. Now, $L_{\alpha}^{\prime}(\alpha, \beta)=L(\alpha, \beta) \cdot l(\alpha, \beta)$, where $l(\alpha, \beta)=\frac{2}{2-\beta}\left[\ln \frac{\alpha-1}{\alpha}+\frac{1}{\alpha-1}\right]$ We observe that the first factor in $L_{\alpha}^{\prime}(\alpha, \beta)$ is positive. The following argument proves that the second factor, namely, $l(\alpha, \beta)$ is also positive, therefore, the first derivation $L_{\alpha}^{\prime}(\alpha, \beta)$ is always positive. For $l(\alpha, \beta)$, we have $l_{\alpha}^{\prime}(\alpha, \beta)=\frac{2}{2-\beta} \cdot \frac{-1}{\alpha(\alpha-1)^{2}}<0$ for $\alpha>1$, and $\lim _{\alpha \rightarrow \infty} l(\alpha, \beta)=0$. Thus, $l(\alpha, \beta)>0$ for $\alpha>1$. The proof of $|\Delta q|$ decreasing in $\alpha$ is now completed. To prove the increasing property of $|\Delta q|$ in $\beta$, is equal to prove the decreasing property of $L(\alpha, \beta)$ in $\beta$, namely $L_{\beta}^{\prime}(\alpha, \beta)<0$ for $0<\beta<2$. In fact, $L_{\beta}^{\prime}(\alpha, \beta)=L(\alpha, \beta)\left[\ln \frac{\alpha-1}{\alpha}\right] \cdot \frac{2 \alpha}{(2-\beta)^{2}}<0$. The limiting value of $|\Delta q|$ concerning $\alpha$ and $\beta$ can be demonstrated by following some formulas mathematically (Noting that $\lim _{\alpha \rightarrow \infty}\left(1-\frac{1}{\alpha}\right)^{-\alpha}=e$.).

Proof of Proposition 8: Part (1) By Propositions 4.1-4.3,

$$
\begin{aligned}
q_{d}^{*} & =z_{d}^{*} y\left(p_{d}^{*}, \theta_{d}^{*}\right) \\
& =z_{d}^{*} a\left(p_{d}^{*}\right)^{-\alpha}\left(\theta_{d}^{*}\right)^{\beta} \\
& =z_{c}^{*} a\left(\frac{\alpha}{\alpha-1} p_{c}^{*}\right)^{-\alpha}\left(\left[\frac{\alpha-1}{\alpha}\right]^{\frac{\alpha}{2-\beta}} \theta_{c}^{*}\right)^{\beta} \\
& =\left[\frac{\alpha-1}{\alpha}\right]^{\frac{2 \alpha}{2-\beta}} z_{c}^{*} a\left(p_{c}^{*}\right)^{-\alpha}\left(\theta_{c}^{*}\right)^{\beta} \\
& =\left[\frac{\alpha-1}{\alpha}\right]^{\frac{2 \alpha}{2-\beta}} q_{c}^{*}
\end{aligned}
$$

Part (2) $q_{d}^{*}<q_{c}^{*}$ by $\alpha>1$ and $0<\beta<2$.

Part (3) By using a similar argument of Proposition 7, the increasing (or decreasing) property of $q_{d}^{*} / q_{c}^{*}$ in $\alpha$ (or in $\beta$ ) can be verified.

Part (4) We can easily get the result by following a similar argument of Part (4) in Proposition 7.

Proof of Proposition 9: Part (1) Substituting Eqs. (5) and (14) into Eqs. (7), (16) and (17) respectively, we get the total profit in the decentralized channel

$$
\Pi_{d}^{*}=\Pi_{d, M}^{*}+\Pi_{d, R}^{*}=\left\{\left[\frac{\alpha-1}{\alpha}\right]^{\frac{2 \alpha}{2-\beta}}+\frac{2}{2-\beta}\left[\frac{\alpha-1}{\alpha}\right]^{\frac{2 \alpha}{2-\beta}-1}\right\} \cdot \Pi_{c}^{*} \#(37)
$$

Part (2) By the definition of Eq. (19), one can easily verify the conclusion.

ISSN: 0010-8189 
Part (3) Let $u(\alpha, \beta) \equiv\left[\frac{\alpha-1}{\alpha}\right]^{\frac{2 \alpha}{2-\beta}}+\frac{2}{2-\beta}\left[\frac{\alpha-1}{\alpha}\right]^{\frac{2 \alpha}{2-\beta}-1}$. Then $\Delta \Pi=1-u(\alpha, \beta)$.

We have

$$
\begin{aligned}
\lim _{\alpha \rightarrow 1} \Delta_{\Pi} & =1-\lim _{\alpha \rightarrow 1} u(\alpha, \beta) \\
& =1-\left\{0+\frac{2}{2-\beta} \cdot 0\right\} \\
& =1 ;
\end{aligned}
$$

and

$$
\begin{aligned}
\lim _{\alpha \rightarrow \infty} \Delta_{\Pi} & =1-\lim _{\alpha \rightarrow \infty} u(\alpha, \beta) \\
& =1-\lim _{\alpha \rightarrow \infty}\left\{\left[1-\frac{1}{\alpha}\right]^{-\alpha \cdot \frac{-2}{2-\beta}}+\frac{2}{2-\beta}\left[1-\frac{1}{\alpha}\right]^{-\alpha \cdot \frac{-2}{2-\beta}}\left[\frac{\alpha-1}{\alpha}\right]^{-1}\right\} \\
& =1-\left\{e^{\frac{-2}{2-\beta}}+\frac{2}{2-\beta} \cdot e^{\frac{-2}{2-\beta}} \cdot 1\right\} \\
& =1-e^{\frac{-2}{2-\beta}}\left[1+\frac{2}{2-\beta} \cdot 1\right] \\
& =1-\frac{4-\beta}{2-\beta} e^{\frac{-2}{2-\beta}}
\end{aligned}
$$

Now we aim to prove the increasing property of $\lim _{\alpha \rightarrow \infty} \Delta_{\Pi}=1-\frac{4-\beta}{2-\beta} e^{\frac{-2}{2-\beta}}$ in $\beta$, which is equal to prove the decreasing property of $l(\beta)$ in $\beta$, or $l^{\prime}(\beta)<0$, where $l(\beta)=\frac{4-\beta}{2-\beta} e^{\frac{-2}{2-\beta}}$. After some algebraic manipulations, we have $l^{\prime}(\beta)=\frac{-4}{(2-\beta)^{3}} e^{\frac{-2}{2-\beta}}<0$ by $0<\beta<2$.

Part (4) For any $\alpha>1$, we have

$$
\begin{aligned}
\lim _{\beta \mapsto 2^{-}} \frac{2}{2-\beta}\left[\frac{\alpha-1}{\alpha}\right]^{\frac{2 \alpha}{2-\beta}-1} & =\lim _{\beta \mapsto 2^{-}} \frac{2}{2-\beta}\left[\frac{\alpha-1}{\alpha}\right]^{\frac{2 \alpha}{2-\beta}} \cdot \frac{\alpha}{\alpha-1} \\
\stackrel{\frac{1}{2-\beta}}{\Rightarrow} & \lim _{t \rightarrow+\infty} 2 t \cdot\left[\frac{\alpha-1}{\alpha}\right]^{2 \alpha t} \cdot \frac{\alpha}{\alpha-1} \\
& =\lim _{t \mapsto+\infty} \frac{2 t}{\left[\frac{\alpha}{\alpha-1}\right]^{2 \alpha t} \cdot \frac{\alpha}{\alpha-1}} \\
& =\lim _{t \mapsto+\infty} \frac{2}{\left[\frac{\alpha}{\alpha-1}\right]^{2 \alpha t} \cdot 2 \alpha \cdot \ln \frac{\alpha}{\alpha-1}} \cdot \frac{\alpha}{\alpha-1} \\
& =0 .
\end{aligned}
$$

It is easy to prove that $\left[\frac{\alpha-1}{\alpha}\right]^{\frac{2 \alpha}{2-\beta}}=0$ and so $\Delta_{\Pi}=1$.

\section{Acknowledgements}

This research was supported by the Tianjin Municipal Education Commission (Grant No. 2018KJ229).

\section{References}

[1] K.M. Shankar, D. Kannan, P.U. Kumar, "Analyzing sustainable manufacturing practices-a case study in Indian context," Journal of Cleaner Production, vol. 164, pp. 1332-1343, 2017.

[2] D. Kannan, "Role of multiple stakeholders and the critical success factor theory for the sustainable supplier selection process," International Journal of Production Economics, vol. 195, pp. 391-418,

ISSN: 0010-8189 
2018.

[3] J.S. Golden, V. Subramanian, J.B. Zimmerman, "Sustainability and commerce trends,"Journal of Industrial Ecology, vol. 15, no. 6, pp. 821-824, 2011.

[4] F. Pan, B. Xi, L. Wang, “Analysis on environmental regulation strategy of local government based on evolutionary game theory," Systems Engineering-Theory and Practice, vol. 35, no. 6, pp. 1393-1404, 2015.

[5] M. Erkoc, S.D. Wu, "Managing high-tech capacity expansion via reservation contracts,"Production and Operations Management, vol. 14, no. 2, pp. 232-251, 2005.

[6] J. Cao, X.B. Wu, G.G. Zhou, "Coordination strategy of green supply chain based on products utility diversity,” Computer Integrated Manufacturing Systems, vol. 17, no. 6, pp. 1279-1286, 2011.

[7] J.B. Sheu, "Bargaining framework for competitive green supply chains under governmental financial intervention," Transportation Research Part E: Logistics and Transportation Review, vol. 47, no. 5, pp. 573-592, 2011.

[8] C.F. Jin, X. Wang, Enterprise decision and incentive strategy of government in remanufacturing green supply chain. Forum on Science and Technology in China, vol. 191, no. 3, pp. 74-80, 2012.

[9] J.B. Sheu, Y.J. Chen, "Impact of government financial intervention on competition among green supply chains," International Journal of Production Economics, vol. 138, no. 1, pp. 201-213, 2012.

[10] D. Ghosh, J. Shah, "A comparative analysis of greening policies across supply chain structures,"International Journal of Production Economics, vol. 135, no. 2, pp. 568-583, 2012.

[11] C.T. Zhang, H.X. Wang, M.L. Ren, "Research on pricing and coordination strategy of green supply chain under hybrid production mode," Computers \& Industrial Engineering, vol. 72, pp. 24-31, 2014.

[12] D. Ghosh, J. Shah, "Supply chain analysis under green sensitive consumer demand and cost sharing contract," International Journal of Production Economics, vol. 164, pp. 319-329, 2015.

[13] B. Li, M. Zhu, Y. Jiang, Z. Li, "Pricing policies of a competitive dual-channel green supply chain," Journal of Cleaner Production, vol. 112, pp. 2029-2042, 2016.

[14] W.G. Zhu, Y.J. He, S.L. Zhao, “Green product design in supply chains under competation,” European Journal of Operational Research, vol. 258, pp. 165-180, 2018.

[15] R. Dai, J.X. Zhang, W.S. Tang, "Cartelization or cost-sharing? Comparison of cooperative modes in a supply chain,” Journal of Cleaner Production, vol. 156, pp. 159-173, 2017.

[16] H.H. Song, X.X. Gao, "Green supply chain game model and analysis under revenue-sharing contract,"Journal of Cleaner Production, vol. 170, pp. 183-192, 2018.

[17] K. Halat, A. Hafezalkotob, "Modeling carbon regulation policies in inventory decisions of a multistage green supply chain: A game theory approach," Computers \& Industrial Engineering, vol. 128, pp. 807-830, 2019.

[18] R.N. Giri, S.K. Mondal, M. Maiti, "Government intervation on a competing supply chain with two green manufacturers and a retailer,” Computers \& Industrial Engineering, vol. 128, pp. 104-121, 2019.

[19] M.S. Asif, H. Lau, D. Nakandala, Y.Q. Fan, H. Hurriyet, “Adoption of green supply chain management practices through collaboration approach in developing countries-From literature review to conceptual framework," Journal of Cleaner Production, vol. 276, DOI: 10.1016/j.jclepro.2020.124191, 2020.

[20] A. Baghalian, S. Rezapour, R.Z. Farahani, Robust supply chain network design with service level against disruptions and demand uncertainties: A real-life case," European Journal of Operational Research, vol. 227, no. 1, pp. 199-215, 2013.

[21] I. Matei, A. Gueye, J.S. Baras, "Flow control in time-varying, random supply chains," Transportation Research Part E, vol. 77, pp. 311-330, 2015.

[22] N. Azad, E. Hassini, "Recovery strategies from major supply disruptions in single and multiple sourcing networks," European Journal of Operational Research, vol. 275, no. 2, pp. 481-501, 2019.

[23] T.M. Choi, T.C.E. Cheng, "Supply chain coordination under uncertainty," Springer, Berlin, Heidelberg, 2011.

[24] J. Li, L. Liu, "Supply chain coordination with quantity discount policy," International Journal of Production Economics, vol. 101, no. 1, pp. 89-98, 2006.

ISSN: 0010-8189

(C) CONVERTER 2021

www.converter-magazine.info 
[25] C.I. Hsu, H.C. Li, "Reliability evaluation and adjustment of supply chain network design with demand fluctuations," International Journal of Production Economics, vol. 132, no. 1, pp. 131-145, 2011.

[26] M.A.Alhaj, D. Svetinovic, A. Diabat, "A carbon-sensitive two-echelon-inventory supply chain model with stochastic demand," Resources, Conservation and Recycling, vol. 108, pp. 82-87, 2016.

[27] Z.M. Chen, Z.X. Chen, "Coordination in the risk-averse OEM supply chain with random supply and demand," Systems Engineering-Theory and Practice, vol. 35, no. 5, pp. 1123-1132, 2015.

[28] T.K. Sasan, A. Maryam, "The development of a green supply chain dual-objective facility by considering different levels of uncertainty," Journal of Industrial Engineering International, vol. 14, pp. 593-602, 2018.

[29] A.G. Campanur, E. Olivares-Benitez, P.A. Miranda, R.E. Perez-Loaiza, J.H. Ablanedo-Rosas, "Design of a logistics nonlinear system for a complex, multiechelon, supply chain network with uncertain demands," Complexity, DOI: 10.1155/2018/4139601, 2018.

[30] S.O. Bhakti, P. Javier, G.C. Canan, A.J. Angel, "Agri-food supply chains with stochastic demands: A multi-period inventory routing problem with perishable products. Simulation Modelling Practice and Theory, https://doi.org/10.1016/j.simpat.2019.101970, 2019.

[31] M.Y. Shan, Y.Y. Hu, X.H. Liu, "Supply Chain Coordination Contract Model Considering Quality Control and Retailer's Loss Aversion Under Stochastic Demand,"East China Economic Management, vol. 33, no. 2, pp. 158-168, 2019.

[32] S.B. Wu, X. Yao, G.D. Wu, "Environmental investment decision of green supply chain considering the green uncertainty," Complexity, DOI: 10.1155/2020/8871901, 2020.

[33] P. Li, C.J. Rao, M. Goh, Z.Q. Yang, "Pricing strategies and profit coordination under a double echelon green supply chain. Journal of Cleaner Production, vol. 278, DOI: 10.1016/j.jclepro.2020.123694, 2021.

[34] B. Keren, "The single-period inventory problem: extension to random yield from the perspective of the supply chain," Omega, vol. 37, no. 4, pp. 801-810, 2009.

[35] Z.H. Yang, H. Chen, Q. Zhao, R.H. Ma, Study on supply chain ripple effect under stochastic demand and production cost disruptions," Chinese Journal of Management, vol. 7, no. 5, 728-738, 2010.

[36] L. Zhu, S.D. Wang, "Game analysis of a two-echelon supply chain with random yield,"Journal of Systems and Management, vol. 20, no. 6, 734-743, 2011.

[37] W.J. Zhang, J.W. Luo, “A study on supply chain coordination under risk of random yield,"Journal of Systems and Management, vol. 22, no. 1, pp. 133-137, 2013.

[38] J.H. Huang, F. Ye, Q. Lin, "Government subsidy mechanism in agricultural supply chain considering capital constrain under random yield," Chinese Journal of Management, vol. 14, no. 2, pp. 277-285, 2017.

[39] D.P. Wang, B.Q. Zhang, L. Wang, "Study on carbon reduction and pricing strategy of closed-loop supply chain considering random collection quantity," Soft Science, vol. 31, no. 8, pp. 86-90, 2017.

[40] T.Ahmadi, M.Mahootchi, K. Ponnambalam, "Optimal randomized ordering policies for a capacitated two-echelon distribution inventory system," Computers \& Industrial Engineering, vol. 124, pp. 88-99, 2018.

[41] S.C. Zhang, J.X. Zhang, "Contract preference with stochastic cost learning in a two-period supply chain under asymmetric information," International Journal of Production Economics, vol. 196, pp. 226-247, 2018.

[42] L. Tang, C. He, K. Jing, Z. Tan, X.W. Qin, "Supply chain network scheduling by considering merge decision with random order interference," Chinese Journal of Management Science, vol. 27, no. 4, pp. 91-103, 2019.

[43] M. Zare, M. Esmaeili, Y.J. He, "Implications of risk-sharing strategies on supply chains with multiple retailers and under random yield," International Journal of Production Economics, vol. 216, pp. 413424, 2019.

[44] E. Anderson, M. Monjardino, "Contract design in agriculture supply chains with random yield," European Journal of Operational Research, vol. 277, no. 3, pp. 1072-1082, 2019.

ISSN: 0010-8189

(C) CONVERTER 2021

www.converter-magazine.info 
[45] Q. Feng, Z.J. Ma, Z.F. Mao, J.G. Shanthikumar, "Multi-stage supply chain with production uncertainty," Production and Operations Management, DOI: 10.1111/poms.13285, 2020..

[46] S.J. Li, Z.B. Zhu, L.H. Huang, "Supply chain coordination and decision making under consignment contract with revenue sharing," International Journal of Production Economics, vol. 120, pp. 88-99, 2009.

[47] N.C. Petruzzi,M. Dada, "Pricing and the newsvendor problem: A review with extensions,"Operations Research, vol. 47, no. 2, pp. 183-194, 1999.

[48] J.Z. Wang, L. Jiang, Z.J. Shen, "Channel performance under consignment contract with revenue sharing," Management Science, vol. 50, no. 1, pp. 34-47, 2004.

[49] Q.H. Zhu, X.Y. Li, S.L. Zhao, "Cost-sharing models for green product production and marketing in a food supply chain," Industrial Management and Data Systems, vol. 118, no. 4, pp. 654-682, 2018. 